\title{
Supporting Information: Responsive Telechelic Block Copolymers for Enhancing the Elasticity of Nanoemulsions
}

\author{
Daniel P. Keane, Matthew D. Mellor, and Ryan Poling-Skutvik* \\ Department of Chemical Engineering, University of Rhode Island, Kingston, RI 02881 \\ E-mail: ryanps@uri.edu
}

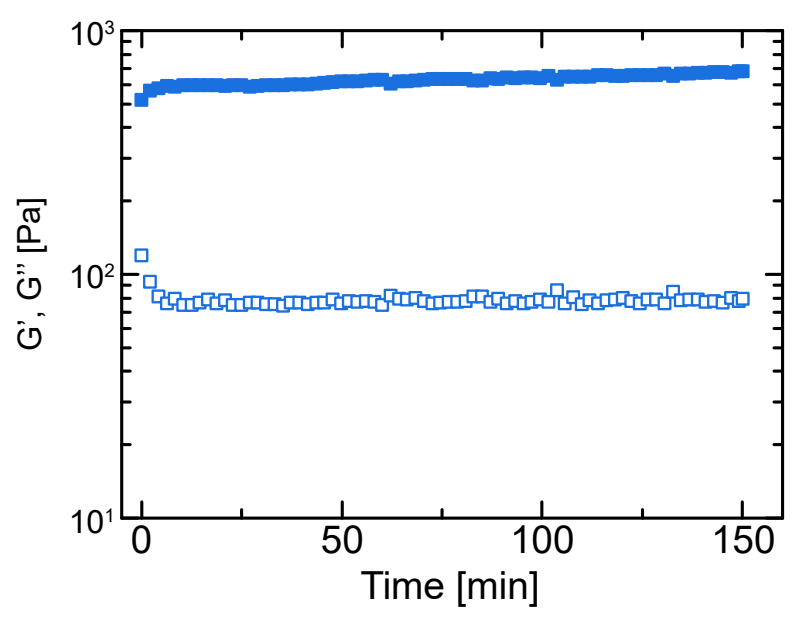

Figure S1: Storage modulus $G^{\prime}$ (closed symbols) and loss modulus $G^{\prime \prime}$ (open symbols) as a function of time at $T=40{ }^{\circ} \mathrm{C}, \omega=10 \mathrm{rad} / \mathrm{s}$, and $\gamma=0.3 \%$. The moduli remain constant over 2.5 hours, indicating that evaporation and creaming are negligible over experimental timescales. 


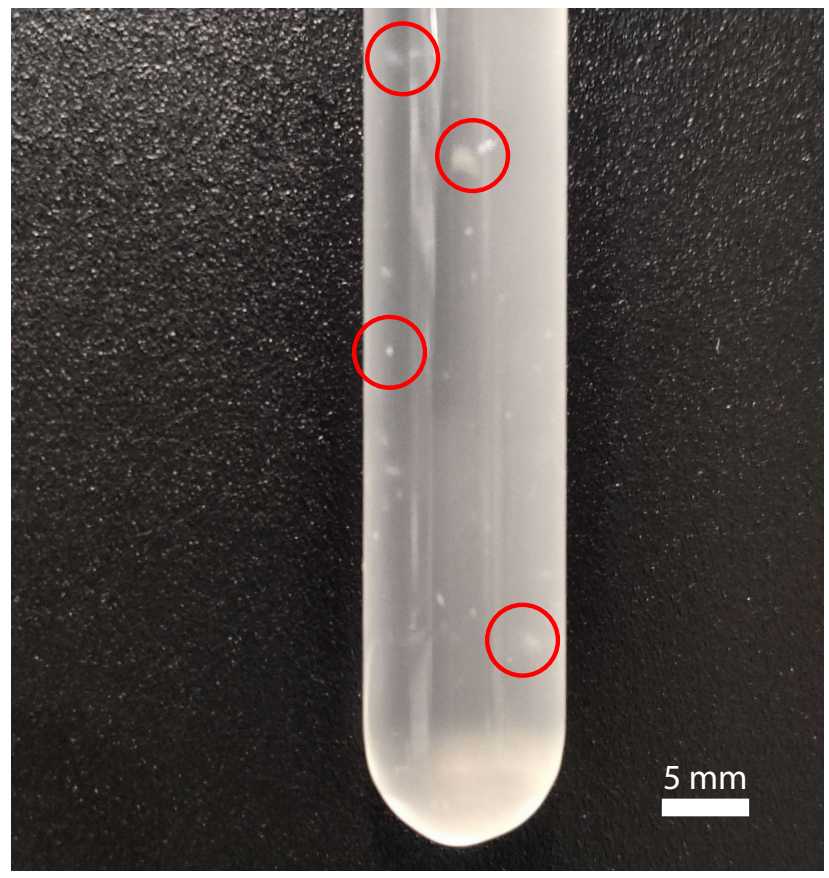

Figure S2: An image of a diluted nanoemulsion originally prepared with $28 \mathrm{~g} / \mathrm{L}$ SEOS$180 / 32$ and then diluted by $\sim 50 \times$ in DI water, revealing long-lived clusters of nanodroplets (red circles). 


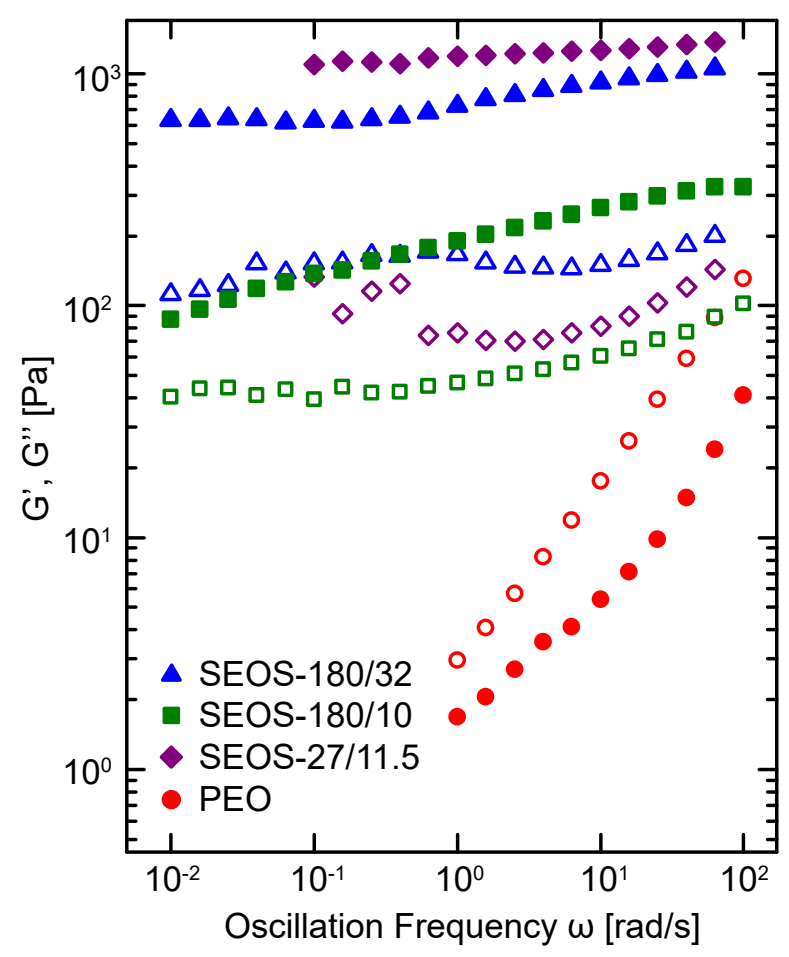

Figure S3: Storage modulus $G^{\prime}$ (closed symbols) and loss modulus $G^{\prime \prime}$ (open symbols) as a function of oscillation frequency $\omega$ for emulsions containing $47 \mathrm{~g} / \mathrm{L}$ of the specified polymers measured at $T=40{ }^{\circ} \mathrm{C}$.

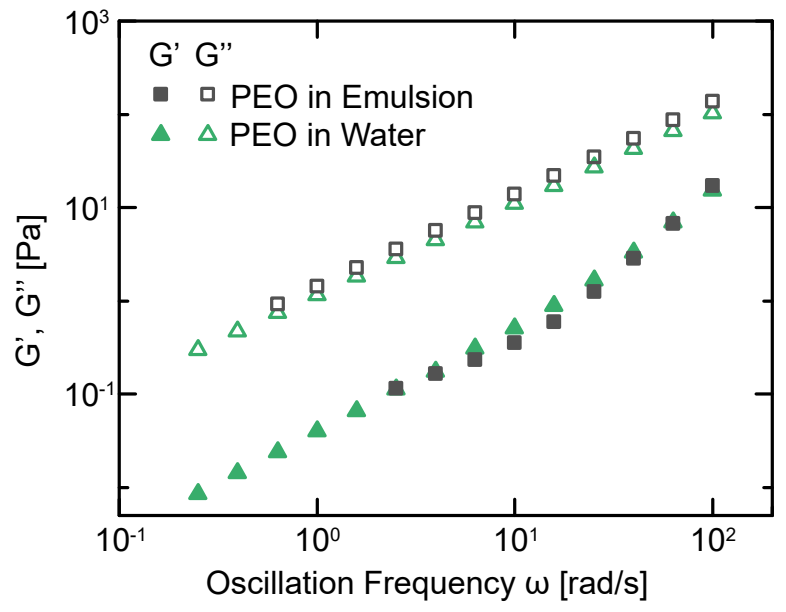

Figure S4: Storage modulus $G^{\prime}$ (closed symbols) and loss modulus $G^{\prime \prime}$ (open symbols) at $T=10{ }^{\circ} \mathrm{C}$ as a function of oscillation frequency $\omega$ for an emulsion containing $47 \mathrm{~g} / \mathrm{L}$ PEO and a PEO-in-water solution at the same effective concentration. 


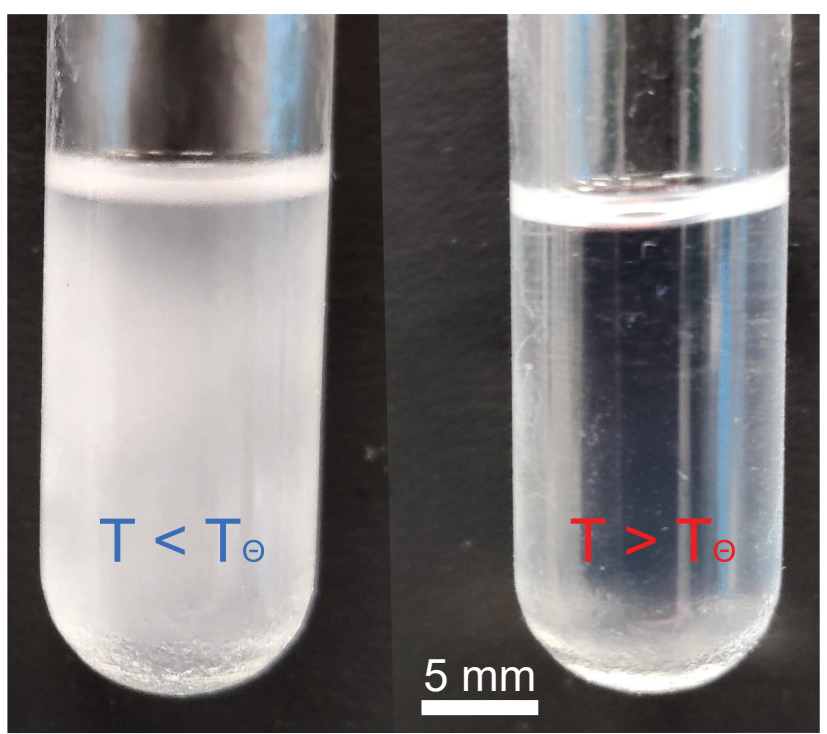

Figure S5: An image of polystyrene $\left(M_{\mathrm{n}}=32.4 \mathrm{kDa}\right)$ dissolved in cyclohexane at a concentration of $87 \mathrm{~g} / \mathrm{L}$ at $T \approx 10{ }^{\circ} \mathrm{C}$ (left) and $21{ }^{\circ} \mathrm{C}$ (right). 